\title{
A new species, Gnathia nkulu sp. n. (Crustacea: Isopoda: Gnathiidae) from southern Africa
}

\author{
Nico J. Smit and Jo G. Van As \\ Department of Zoology and Entomology, University of the Free State, PO Box 339, Bloemfontein, 9300, South Africa
}

Key words: Gnathia nkulu, description, taxonomy, morphology

\begin{abstract}
A new species, Gnathia nkulu sp. n. is described from material collected off the South African coast at 80-200m depth. It differs from the intertidal species Gnathia africana Barnard, 1914 in that the mediofrontal process is not deeply divided into two lobes, article 2 of the pylopod is rounded and small wart-like tubercles and long simple setae are present on both the cephalosome and pereon.
\end{abstract}

The coastline of southern Africa is known for its unique and diverse vertebrate and invertebrate fauna with many species being endemic to this region. So far only four species of temporary fish parasites of the isopod family Gnathiidae have been described from southern Africa, thus not reflecting this diversity. A similar situation occurred in Australia in the late 1970s. Holdich and Harrison (1980) attributed the low number of described species at that time to poor sampling effort and ignorance of the smaller elements of the macrofauna. After extensive sampling Cohen and Poore (1994) proved them right by describing 29 species from southeastern Australia. The same situation may also be found in southern Africa.

While working on the gnathiid collection of the South African Museum, Cape Town, specimens of the genus Gnathia Leach, 1814 that do not correspond to any description of the known species from South Africa (see Kensley 1978) as well as other parts of the world were found. These specimens, wrongly identified as Gnathia africana Barnard, 1914, will be described herein as a new species. This description brings the total number of gnathiids found from southern Africa up to five with the other records being those of Barnard (1914a,b, 1920, 1925) describing Gnathia africana; Gnathia spongicola Barnard, 1920; Gnathia disjuncta Barnard, 1920 and Caecognathia cryptopais (Barnard, 1925).

\section{MATERIALS AND METHODS}

The specimens used in this study were collected from various localities along the South African south coast between 1972 and 1978 by means of dredges of $80-200 \mathrm{~m}$ depth. Since most of the material was fixed in $70 \%$ ethanol for more than 20 years before examination, special attention was given to the cleaning of the specimens. For light as well as scanning electron microscopy, specimens were prepared following the same methods described elsewhere (see Smit et. al. 1999). For the purpose of this description, we followed the anatomical terminology used by Monod (1926) and the numbering of pereonites and pereopods adopted by Cohen and Poore (1994).

\section{RESULTS}

Gnathia nkulu sp. n.

Figs. 1-15

\section{Adult male}

Description: Total length of holotype: $3.7 \mathrm{~mm}$. Total lengths of paratypes: $3.35-4.9 \mathrm{~mm}$ (mean $4.1, \mathrm{n}=20)$. Total lengths of other material: $3.3 \mathrm{~mm}(\mathrm{n}=1), 4.9 \mathrm{~mm}$ $(\mathrm{n}=1)$.

Cephalosome. Rectangular, 1.3 times as wide as long, very deep V-shaped dorsal sulcus (Fig. 12), extending medianly to almost middle of cephalosome, lateral margins straight, posterior margin slightly concave, cephalosome with few dorsal setae (Fig. 1). Sensory pits and small wart-like tubercles distributed randomly over dorsal surface as well as ventrally on lateral sides of buccal cavity of cephalosome (Fig. 12). Long simple setae sparsely distributed over cephalosome. Well-developed oval-shaped, compound eyes on lateral margin of cephalosome, length of eye less than a third of cephalosome (Fig. 3). Paraocular ornamentation consisting of eight to ten small tubercles with simple setae dorsal to eye (Fig. 13). Semicircular row of tubercles on lateral sides and posterior half of dorsal cephalosome. Elongated posterior median tubercle present.

Frontal border. Slightly produced superior frontolateral process conical, with three long simple setae on process (Fig. 2). Mediofrontal process inferior, small concave median notch, minute tubercles on lateral margins (Fig. 14). No inferior frontolateral process. External scissura deeply excavated. Supraocular lobe prominent, extending laterally.

Antennae. Antenna 2 longer than antenna 1 (Fig. 2). Antenna 1 with three peduncle articles, with third one largest, flagellum with five articles, article 2 and 3 largest, articles 3 and 4 with one aesthetascs setae each, article 5 terminating in one aesthetascs and three to five simple setae, few setae on each article (Fig. 4). Antenna 2 with five peduncle articles, article 5 largest, flagellum with seven articles, article 1 largest, article 7 


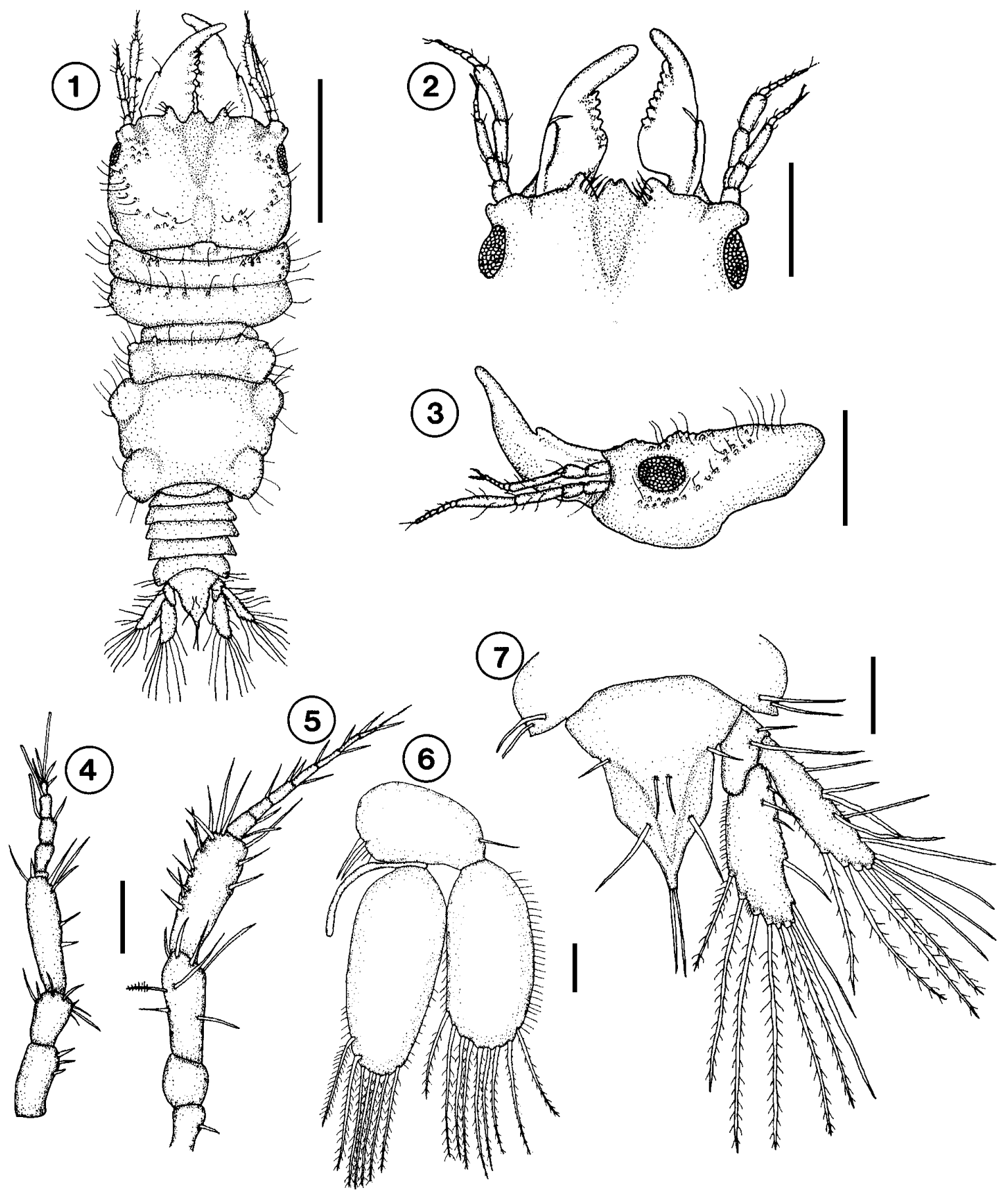

Figs. 1-7. Microscope projection drawings of a male Gnathia nkulu sp. n. (SAM-A19314). Fig. 1. Full length dorsal view. Fig. 2. Frontal border and mandibles. Fig. 3. Lateral view of cephalosome, antennae and mandible. Fig. 4. First antenna. Fig. 5. Second antenna. Fig. 6. Left pleopod 2 with appendix masculina. Fig. 7. Telson and uropods. Scale bars: Fig. $1=1$ mm; Figs. $2,3=500$ $\mu \mathrm{m}$; Figs. $4-7=100 \mu \mathrm{m}$. 


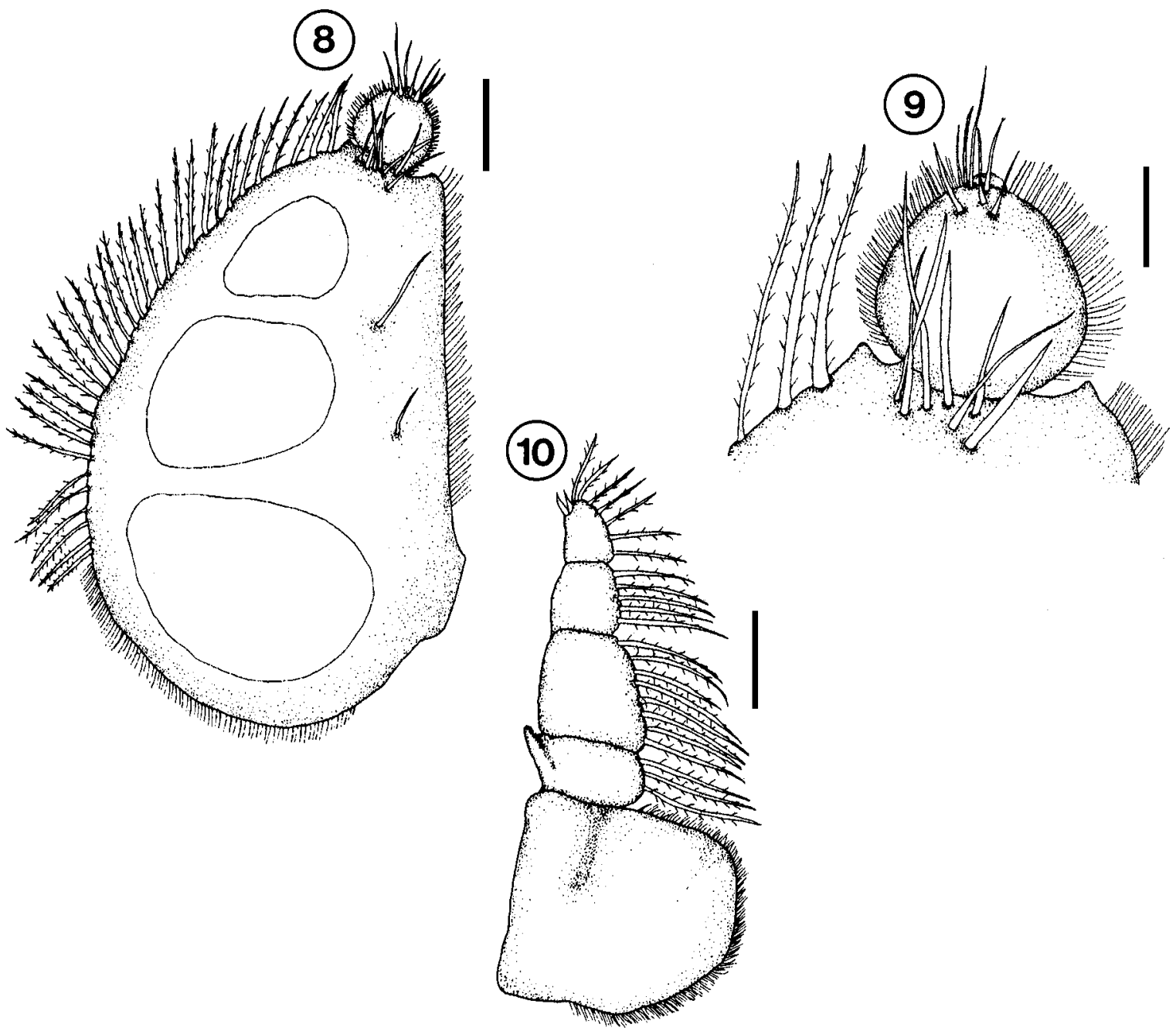

Fig. 9. Articles 2 and 3 of pylopod. Fig. 10. Maxilliped. Scale bars: Figs. $8,10=100 \mu \mathrm{m}$; Fig. $9=50 \mu \mathrm{m}$.

terminating in three to four simple setae, few setae on each article, except article 5 of peduncle with 15 to 20 setae (Fig. 5).

Mandible. Long, almost same length as cephalosome, more than twice as long as wide, curved inwards with seven to nine processes on dentate blade, tussles of setae between processes (Figs. 2, 15). Apex conical, distally raised in lateral view at $45^{\circ}$ (Fig. 3). Incisor present, terminating in acute point. Single mandibular seta extending from base of incisor process. Prominent unarmed carina, forming ridge on lateral margin extending from basal neck to halfway along mandible. Basal neck quarter of total mandible length. Pits on dorsal and ventral sides of mandible. Internal lobe and pseudoblade absent.

Maxilliped. Five-articled, proximal article the largest, distal four articles with plumose setae on external margin in order of 3-8-5-7 (Fig. 10). Palp 3.5 times as long as wide. Endite contiguous with article 2, reaching article 3. Simple setae on external border of endite. No coupling hooks.

Pylopod. Three articles, flat, overlapping. First article greatly enlarged, internal border fringed with plumose setae, external setae short and simple, two simple setae posteriorly near external border and seven distally (Fig. 8). Three areolae. Second article round, as long as wide, margins setose, seven simple setae distally on ventral surface (Fig. 9). Third article minute, with fringing setae.

Pereon. Almost one and a half times as long as wide, wider than cephalosome (Fig. 1). Pereonite 1 fused with cephalosome, dorsally visible, not reaching lateral margins, divided into three regions by posterior margin of cephalosome, anterior border with convex median evagination, posterior margin straight (Fig. 1). Pereonite 2 and 3 of similar size, widest part of body, lateral 

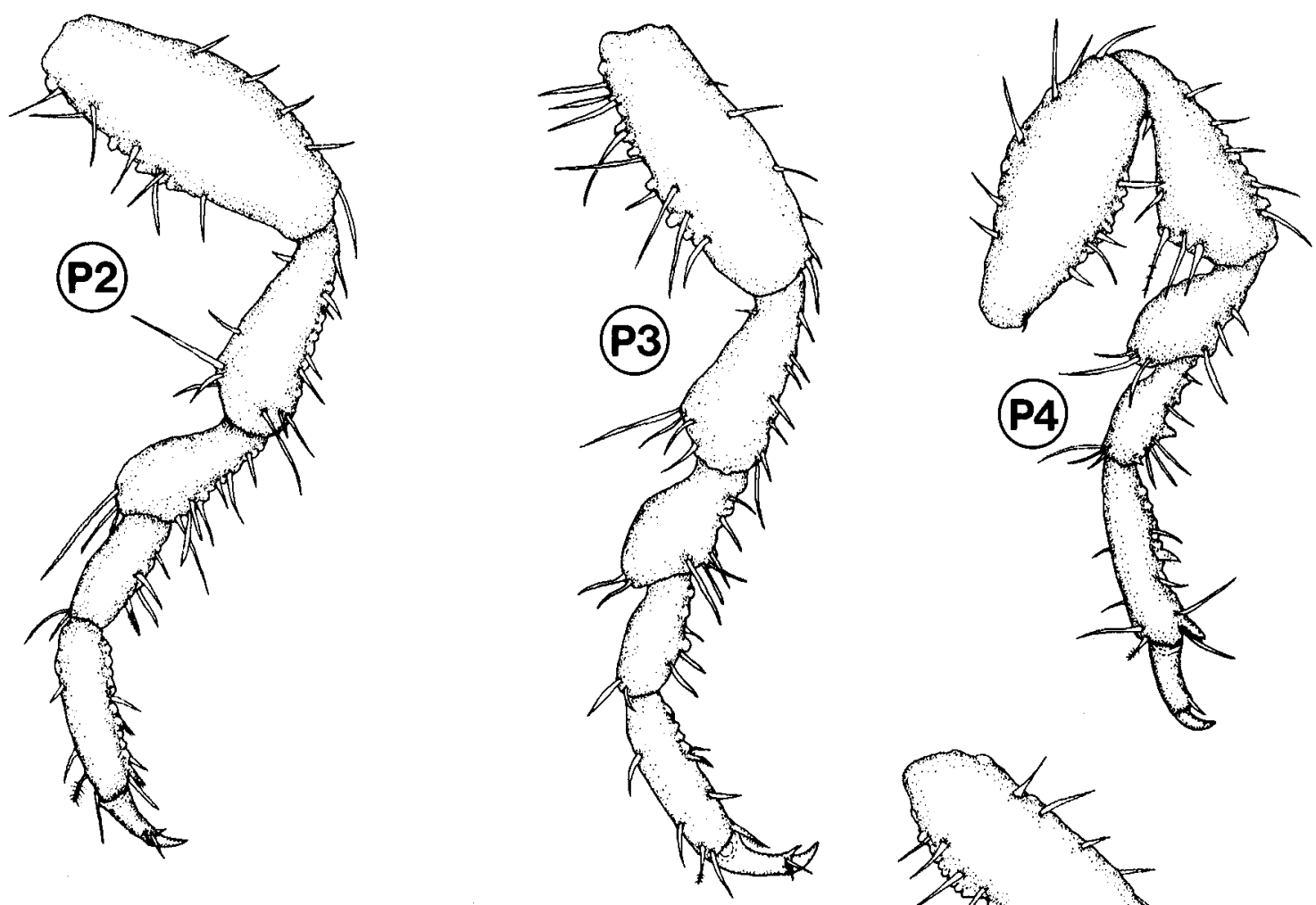

11
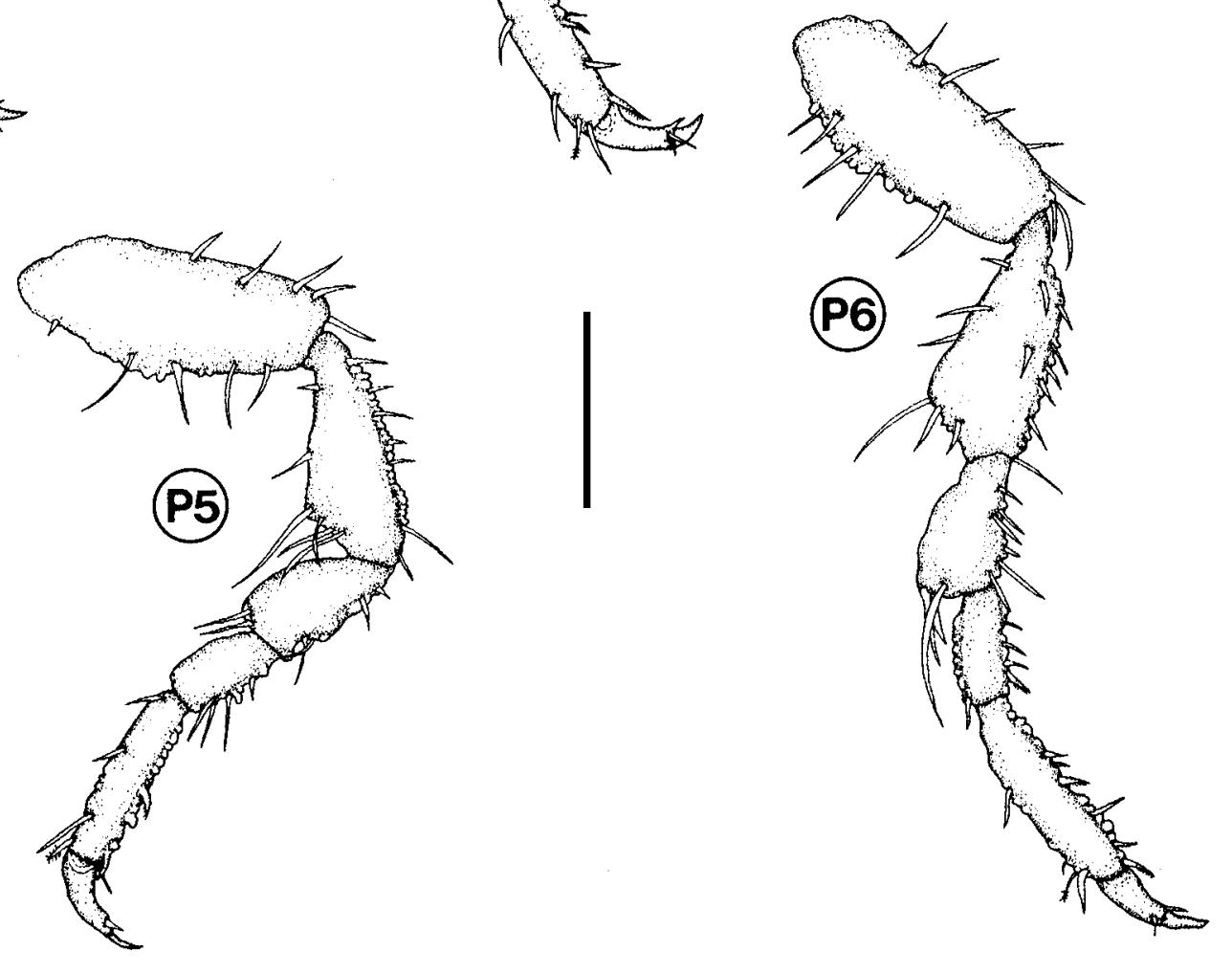

Fig. 11. Microscope projection drawings of pereopods 2 to 6 (P2-P6) of a male Gnathia nkulu sp. n. (SAM-A43160). Scale bar: $200 \mu \mathrm{m}$.

margins pointing anteriorly. Pereonite 3 with anterior constriction, but not separating lateral sides of pereonites 2 and 3. Prominent anterior constriction of pereonite 4 separating it from pereonite 3. Pereonite 4 with shallow median groove. Pereonite 5 and 6 not fused, but separation not distinct. Pereonite 6 at least twice as long as other pereonites, 1.3 times as long as wide, posterior margin deeply concave, without lobuii. Pereonite 7 dorsally visible, small with rounded posterior margin, overlapping first pleonite. Sensory pits, simple setae and small wart-like tubercles randomly distributed on pereon. 

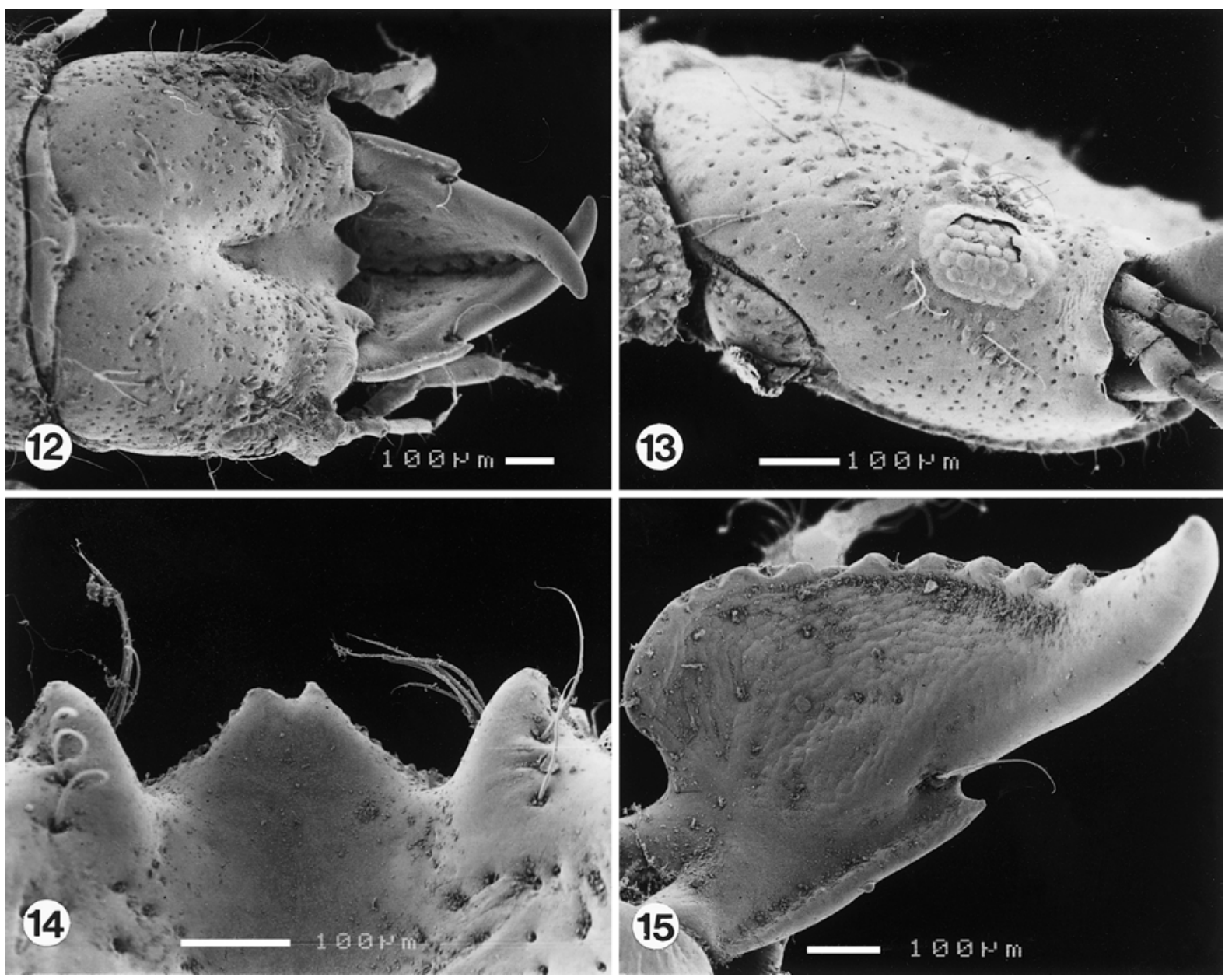

Figs. 12-15. Scanning electron micrographs of a male Gnathia nkulu sp. n. Fig. 12. Dorsal view of cephalosome. Fig. 13. Lateral view of cephalosome. Fig. 14. Dorsal view of frontal border with simple setae. Fig. 15. Dorsal view of right mandible.

Pleon. Pleon and pleotelson slightly less than a fifth of total length (Fig. 1). All five pleonites dorsally visible, epimera not distinct.

Pleotelson. Triangular, longer than wide, lateral margins tapering in two steps towards apex, three pairs of simple setae on dorsal surface, distal apex terminating in pair of simple setae (Fig. 7).

Pereopods. Pereopod 2 basis elongated with eight to twelve simple setae as well as a few tubercles on anterior and four to seven simple setae on posterior side. Ischium as long as basis but not as wide, three to five anterior setae and posterior tubercles with simple setae in between (Fig. 11). Merus half the length of ischium with anterior bulbous protrusion, simple setae on bulbous protrusion, posterior margin with tubercles as well as simple setae. Carpus of almost same size and shape as merus, but without anterior bulbous protrusion. Propodus about twice the length of carpus, prominent tubercles fringe posterior side, two elongated spines ending in sharp points situated on middle and distal part of posterior side respectively, only a few simple setae anteriorly with single plumose seta distally. Dactylus half the length of propodus, terminates in sharp posterior pointing unguis, prominent spine on posterior side proximal to unguis, few simple setae on dorsal and ventral sides of spine. Pereopods 3 to 6 similar in basic form to pereopod 2, but differ in number and placement of setae (see Fig. 11) as well as in direction, pereopods 4 to 6 directed posteriorly and pereopods 2 and 3 anteriorly.

Pleopods. Exopod and endopod of almost similar size. Both fringed distally with seven to nine long plumose setae, few shorter simple setae on lateral margins. Plumose setae almost as long as pleopod. Pleopod 2 endopod with appendix masculina almost half the length of rami (Fig. 6).

Penes. Prominent with two contiguous papillae, as long as wide. 
Uropods. Rami extending beyond apex of pleotelson, endopod longer and wider than exopod, both with long fringing setae (Fig. 7). Endopod with inner six plumose setae, four to six simple setae on dorsal surface. Exopod with inner four plumose setae, rest of setae simple. Uropodal basis with two simple setae.

T y p e m a t e r i a 1 : Holotype: In the collection of the South African Museum, Cape Town (SAM-A19314).

T y p e 1 o c a 1 i t y : Off the south coast, east of Port Alfred (33 $\left.39.3^{\prime} \mathrm{S}, 27^{\circ} 11.6^{\prime} \mathrm{E}\right)$

O t h e r 1 o c a 1 i t i e s : Off Port Alfred (3339.3'S, $\left.27^{\circ} 11.6^{\prime} \mathrm{E}\right)$ and $\left(35^{\circ} 22^{\prime} \mathrm{S}, 22^{\circ} 31^{\prime} \mathrm{E}\right)$.

Type host of parasitic larvae: Unknown.

De p o s ition of ty p e s: Holotype: In the collection of the South African Museum, Cape Town (1 male, SAMA19314). Paratypes: In the collection of the South African Museum, Cape Town (19 males and 7 larvae, SAMA43160) and in the collection of the Institute of Parasitology, ASCR, České Budějovice, Czech Republic (1 male, PAÚ AVČR 1981).

O t h e r m a t e r i a 1 : In the collection of the South African Museum, Cape Town (1 male, SAM-A19313), (1 male, SAM-A14859).

E t y m o l o g y: The Xhosa word "nkulu" was chosen as this means large in the language of this southern African tribe.

\section{DISCUSSION}

Of all the southern African species, Gnathia nkulu is very similar to Gnathia africana in size and overall body proportions, particularly the mandibles, pereon and pleotelson. Gnathia nkulu differs in that the mediofrontal process is not deeply divided into two lobes, article 2 of the pylopod is rounded and small wart-like tubercles and long simple setae are present on both the cephalosome and pereon.

Gnathia nkulu and G. africana populations do overlap in their distribution, but there is a big difference in the depth at which they occur. Gnathia africana are found in the intertidal zone (Barnard 1914a, Smit et al. 1999) and G. nkulu in water of 80-200m deep.

Gnathia nkulu shows some resemblance to the Australian species Gnathia biorbis Holdich et Harrison, 1980, especially in the shape of the frontal border. Both species have conical superior frontolateral processes and an inferior mediofrontal process with a slightly indented apex (Holdich and Harrison 1980). Our species differs from the Australian species in the shape of the pleotelson, the presence of a semicircular row of tubercles on the lateral sides of the cephalosome, the presence of long plumose setae on the rami of the pleopods and in the endopod of pleopod 2 having an appendix masculina.

Acknowledgements. The authors thank Ms. Michelle van der Merwe of the South African Museum, Cape Town, for making the gnathiid material available for examination. This study was funded by the marine resource program of the National Research Foundation (NRF) of South Africa.

\section{REFERENCES}

BARNARD K.H. 1914a: Contributions to the crustacean fauna of South Africa. 1. Additions to the marine Isopoda. Ann. S. Afr. Mus. 10: 197-230.

BARNARD K.H. 1914b: Contributions to the crustacean fauna of South Africa. 3. Additions to the marine Isopoda, with notes on some previously incompletely known species. Ann. S. Afr. Mus. 10: 325a-358a, 359-442.

BARNARD K.H. 1920: Contributions to the crustacean fauna of South Africa. 6. Further additions to the list of marine Isopoda. Ann. S. Afr. Mus. 17: 319-438.

BARNARD K.H. 1925: Description of a new species of Gnathia (Crustacea, Isopoda) from South Africa. Ann. Mag. Nat. Hist. 15: 417-418.

COHEN B.F., POORE G.C.B. 1994: Phylogeny and biogeography of the Gnathiidae (Crustacea: Isopoda) with descriptions of new genera and species, most from southeastern Australia. Mem. Mus. Victoria 54: 271-397.

HOLDICH D.M., HARRISON K. 1980: The crustacean isopod genus Gnathia Leach from Queensland water with descriptions of nine new species. Aust. J. Mar. Freshwater Res. 31: 215-240.

KENSLEY B. 1978: Guide to the Marine Isopods of Southern Africa. The Rustica Press (PTY.) LTD., Wynberg, Cape, $173 \mathrm{pp}$.

MONOD T. 1926: Les Gnathiidae. Essai monographique (Morphologie, Biologie, Systématique). Mem. Soc. Sci. Nat. Maroc 13: 1-668.

SMIT N.J., VAN AS J.G., BASSON L. 1999: A redescription of the adult male and praniza of Gnathia africana Barnard, 1914 (Crustacea, Isopoda, Gnathiidae) from southern Africa. Folia Parasitol. 46: 229-240. 